\title{
Experimental and Theoretical Studies on a Thiocarbamide Derivative Containing Schiff Base Groups
}

\author{
Pu Su Zhao," De Long Shao, Jing Zhang, Yi Wei," and Fang Fang Jian" \\ Jiangsu Kev Laboratory for Chemistrv of Low-Dimensional Materials. Huaivin Nomal Lniversity, Huaian, \\ Jiangst, 223300, P. R. China. "E-mail: zhaopusutal $163 . \mathrm{com}$

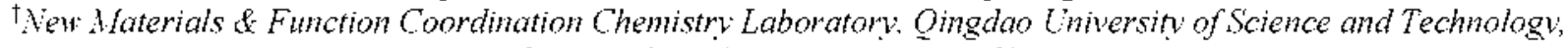 \\ Qingdao Shandong 266042, P. R. China \\ Received Februarv 20, 2009. Accepted Mav 28, 2009
}

Key Words: Sỵthesis. Crỵstal structure. Density functional calculations. Electronic absorption spectra. Thermody namic property

Thiocarbamide group is a key element with common stnicture in a variety of natural and synthetic compounds with interesting biological or chemical properties and therefore has been known for its important medicinal. ${ }^{1-3}$ bioorganic. ${ }^{4}$ supramolecular chemistr applications. Most recently. thiocarbamide derivatives have been used for asymmetric sy nthesis and they play an important role as chiral catalysts for highly enantioselective michael reactions and a new type of herbicides for weed control. ${ }^{8}$ Sparked by above reasons, our group persists in synthesizing and making studies on thiocarbamide derivatives. ${ }^{9-13}$ On the other hand. Schiff base ligand possess N-donor with favorable coordination ability and easily constructs hydrogen bonds in supramolecular chemistry. ${ }^{14}$ In addition. Schiff base complexes have been extensively studied in great detail as a result of their prospective applications in catalysis. magnetic properties. molecular architectures and materials chemistry by coordination chemists at all times. ${ }^{15-18}$ Herein. we report the experimental results about the title compound. 1.5-bis[1-(4-nitrophenyl)ethylidene] thiocarbonohydrazide, which is a typical thiocarbamide derivative containing Schiff base groups. We also report the theoretical calculational results about the title compound. Since with the recent advances in compute hardware and software. it is possible to correctly describe physico-chemical properties of relatively small molecules accuracy ${ }^{15-2}$ using density functional theory (DFT).$^{33-55}$ The comparisons between the experiments and the calculations about the title compound have also been revealed in the paper.

Crystal structure of the title compound crystallizes in triclinic system. space group $P-1$. with lattice parameters $a=$ $7.858(4)$ A. $b=16.170(7)$ A. $c=16.842(7)$ A. $a=102.540(9)^{\circ}$. $\beta=100.005(8)^{\circ}, \gamma=101.432(8)^{\circ}, r=1994.3(16) A^{3}$. . fr $=$ $836.87\left(\mathrm{C}_{34} \mathrm{H}_{36} \mathrm{~N}_{12} \mathrm{O}_{16} \mathrm{~S}_{2}\right), Z=2, D c=1.394 \mathrm{~g} / \mathrm{cm}^{3} . \mu=0.204$ $\mathrm{mm}^{-1}, F(000)=872, \mathrm{GOF}=0.926 . R_{1}=0.1139, w R_{2}=0.2387$. A displacement ellipsoid plot with the atomic numbering scheme is shown in Figure 1.

The stnicture of the title compound contains two cry stallographically independent water molecules and two 1,5-bis[1(4-nitrophenyl)ethylidene] thiocarbonohydrazide molecules. hereafter named $\mathrm{Tl}$ [containing $\mathrm{C}(1) \sim \mathrm{C}(6)$ phenyl ring] and $\mathrm{T} 2$ [containing $\mathrm{C}(18) \sim \mathrm{C}(23)$ phenyl ring]. In $\mathrm{T} 1$ and $\mathrm{T} 2$, all of the bond lengths and bond angles are different. For example. $\mathrm{S}=\mathrm{C}$ bond length of $1.682(12) \mathrm{A}$ in $\mathrm{Tl}$ is longer than that of 1.658 (11) $A$ in T2 and both of them are shorter than that found in the sinular structure $[1.704(3)] .{ }^{101}$ In $\mathrm{T} 1$ and $\mathrm{T} 2$, despite some differences, all of the bond lengths and bond angles in the phenyl rings are in the normal range. As for the N-C single bonds connected with the N-N bonds. in T1. the two bond lengths of $\mathrm{N}-\mathrm{C}$ are 1.332 (12) $\mathrm{A}$ and $1.36+$ (12) $\mathrm{A}$. respectively. while in $\mathrm{T} 2$, the two $\mathrm{N}-\mathrm{C}$ bond lengths are $1.329(12) \mathrm{A}$ and 1.345 (I l) $\AA$. respectively: These four N-C bond lengths are corresponding to those found in a similar structure of 1.5-bis (9-antluracylidene)thiocarbonolydrazide. ${ }^{26}$ where the two N-C bond lengths are $1.332(2)$ and $1.355(3) \AA$. respectively. In view of the bond lengths of $\mathrm{N}-\mathrm{N}$ and $\mathrm{C}=\mathrm{N}$ in $\mathrm{T} 1$ and $\mathrm{T} 2$ (see supporting information $\$ 1$ ), all of which are also in agreement with those in the above cited structure $[\mathrm{N}-\mathrm{N} 1.380(2)$ and $1.381(2) \AA . C=N 1.250(3)$ and $1.266(2) \AA]{ }^{26}$ Four phenyl rings in $\mathrm{T} 1$ and $\mathrm{T} 2$ are almost planar each other. The dihedral angles between the two phenyl rings in $\mathrm{T} 1$ is $15.34(2)^{\circ}$ and in $\mathrm{T} 2$ is $10.49(2)^{\circ}$. The dihedral angles between the phenyl ring of $\mathrm{C}(1)-\mathrm{C}(6)$ in $\mathrm{T} 1$ and the two phenyl rings in $\mathrm{T} 2$ are $16.65(2)$ and $6.42(2)^{\circ}$. respectively. The phenyl ring $C(12) \sim$ $\mathrm{C}(17)$ in $\mathrm{Tl}$ forms the dihedral angles with the two phenyl rings in T2 being 7.29 (2) and $9.21(2)^{\circ}$. respectively.

In the crystal lattice. there are some intermolecular and intranolecular supramolecular interactions and the two water molecules take part in the formation of these supramolecuar interactions (see supporting information S2), which stabilize

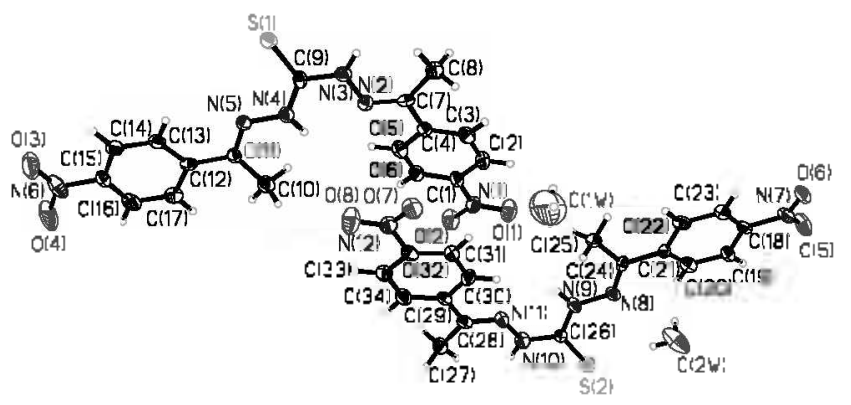

Figure 1. The molecular structure with the atomic numbering for the title compound. 
the crystal structure in the solid state.

One molecular stnicture of the title compound was selected to be optimized at DFT-B3LYP/6-31G* level of theory. Comparisons between the theoretical values with the experimental ones indicate that most of the optimized bond lengths are slightly larger than the experimental values, as the theoretical calculations are performed for isolated a molecule in gaseous phase and the experimental results are for a molecule in a solid state. The geometry of the solid-state structure is subject to intermolecular forces. such as van der Waals interactions. crystal packing forces and hydrogen-bond forces. The biggest bond length differences between the experimental and the predicted values in $\mathrm{Tl}$ is $0.035 \mathrm{~A}$ for $\mathrm{N}(4)-\mathrm{C}(9)$ bond and in $\mathrm{T} 2$ is $0.057 \AA$ for $\mathrm{N}(10)-\mathrm{C}(26)$ bond. In view of the bond angle difference between experimental and theoretical values. the biggest difference in $\mathrm{T} 1$ is $4.7^{\circ}$ for $\mathrm{C}(9)-\mathrm{N}(3)-\mathrm{N}(2)$ bond angle and in $\mathrm{T} 2$ is $3.6^{\circ}$ for $\mathrm{C}(32)-\mathrm{C}(33)-\mathrm{C}(34)$ bond angle. The differences maybe since that. in the crystal structure, all the atoms of $N(4) . N(10) . N(2) . N(3)$ and $C(33)$ take part in the formation of hydrogen bonds (see S2). while in theoretical calculations. there was none hydrogen bond considered. Despite of these differences the optimized geometry can reproduce the crystal structure on the whole.

Based on the optimized stnicture of the title compound at B3LYP/6-31G* level of theory. the NPA atomic charge distributions for the non-hy'drogen atoms were calculated and the results are listed in Table 1 . The atomic numbering scheme is the same as that in $\mathrm{T} 1$ molecule.

Seen from Table 1. on the one hand. for NPA atomic charge distributions of the non-hydrogen atoms. atomic electronegativity plays important roles. Namely, between the two connecting atoms, the atom having bigger electronegativity will carry negative charges. while the atom having smaller electronegativity will carry positive charges. For example. when a carbon atom is connected with a nitrogen atom. the carbon atomic charges are positive values and the nitrogen atomic charges are negative values, since the nitrogen atom has bigger electronegativity than the carbon atom. However. when a nitrogen atom is joined with an oxygen atom. the nitrogen atom has positive charges and the oxygen atom has negative charges. since the oxygen atom has bigger electronegativity than the nitrogen atom. So, for the title compound. the atoms of $\mathrm{C}(7), \mathrm{C}(9)$ and $\mathrm{C}(11)$ have positive atomic charges and $N(2)$. N(3), N(4) and $N(5)$ have negatively atomic charges.
As regards two carbon atonts joined to two nitro-groups, atoms $C(1)$ and $C(15)$ carry positive charges. $N(1)$ and $N(6)$ also carry positive charges. while four oxygen atoms carry negative charges. $\mathrm{C}(8)$ and $\mathrm{C}(10)$ in methyl groups and other carbon atoms in two phenyl rings all carry negative charges. since the hydrogen atom has smaller electronegativity than the carbon atom. On the other hand, for the non-hydrogen atoms in Table 1, although atoms of $N(3) . N(4) . C(8)$ and $C(1)$ in two methyl groups and the some carbon atoms in two phenyl rings have bigger negative charge values. steric effect hinders them to coordinate with metallic ions further. For the atoms of $\mathrm{S}(1), \mathrm{N}(2)$. N(5) and four oxygen atoms in two nitrogroups, they all carry negative atomic charges and there is none steric effect hindered them, which results in these atoms being able to coordinate with metallic ions further. Namely. the title compound is a good multidentate ligand and it has the potential to construct interesting complexes with various metallic ions, which supports one of our original ideas of the synthesis.

Electronic absorption spectra were calculated by using TD-DFT method at B3LYP/6-31G* level based on the optimized geometry. The experimental electronic absorption spectra values and theoretical electronic absorption spectra information are both given in Table 2 . Seen from Table 2, the experiment and theoretical calculations both obtain two absorption bands: one is narrow and another is broad. In experiments. the broad band is from $245 \mathrm{~nm}$ to $255 \mathrm{~nm}$ and the narrow peak at $349 \mathrm{~lm}$, while contrary to the experiments, in calculations. the narrow peak is at $242 \mathrm{~nm}$ and the broad band is from $380 \mathrm{~nm}$ to $386 \mathrm{~nm}$. In addition, compared with the experimental data. although the predicted narrow peak has some blue shifts and the predicted broad band has some red shifts. the intensity order of the two predicted bands are the same as the experiments. Namely. TD-DFT method at B3LYP/ $6-31 \mathrm{G}^{*}$ level can predict the electron transition spectra approximately. The detailed electronic transition modes corresponding to each absorption peak are also listed in Table 2. Based on the optimized structure. molecular orbital coefficients analyses indicate that the frontier molecular orbitals are mainly composed of $p v$ and $p z$ atomic orbitals and electronic absorption spectra aforementioned are mainly assigned to $n-\pi^{*}$ and $\pi-\pi^{*}$ electron transitions. Figure 2 shows some frontier molecular orbitals surfaces of the title compound. Seen from Figure 2. except the two methyl groups, the other groups, such as the

Table 1. NPA atomic charge distributions for the non-hydrogen atoms

\begin{tabular}{|c|c|c|c|c|c|}
\hline Atom & Charges(e) & Atom & Charges $(e)$ & Atom & Charges $(e)$ \\
\hline$S(1)$ & -0.14813 & $C(1)$ & 0.05929 & $C(12)$ & -0.06046 \\
\hline$N(2)$ & -0.29106 & $\mathrm{C}(2)$ & -0.20297 & $C(13)$ & -0.19051 \\
\hline$N(3)$ & -0.41642 & $C(3)$ & -0.21675 & $C(14)$ & -0.20808 \\
\hline$N(4)$ & -0.41840 & $C(4)$ & -0.05821 & $C(15)$ & 0.05901 \\
\hline$N(5)$ & -0.23079 & $C(5)$ & -0.20007 & $C(16)$ & -0.20637 \\
\hline$C(9)$ & 0.21749 & $\mathrm{C}(6)$ & -0.20716 & $C(17)$ & -0.22020 \\
\hline$N(1)$ & 0.51114 & $C(7)$ & 0.23447 & $C(11)$ & 0.23199 \\
\hline$N(6)$ & 0.51113 & $\mathrm{C}(8)$ & -0.75325 & $C(10)$ & -0.75242 \\
\hline$O(1)$ & -0.38145 & $O(2)$ & -0.38109 & $O(3)$ & -0.38213 \\
\hline$O(4)$ & -0.38635 & & & & \\
\hline
\end{tabular}


Table 2. Experimental and theoretical electronic absorption spectra values

\begin{tabular}{|c|c|c|c|c|}
\hline \multicolumn{2}{|c|}{ Exp. } & \multicolumn{3}{|c|}{ Calc. at BiL YP/6-31G* level } \\
\hline Wavelength (11m) & $\log \varepsilon$ & Wavelength (mun) & Oscillator strength & Transition \\
\hline $245-255$ & 3.34 & 242 & 0.1101 & $\mathrm{HOMO}-2 \rightarrow \mathrm{LIMO}+4$ \\
\hline 349 & 3.48 & 380 & 0.2967 & $\begin{array}{l}\text { HOMO- }-\rightarrow \text { LUMO } \\
\text { HOMO-l } \rightarrow \text { LUMO+I } \\
\text { HOMO-1 } \rightarrow \text { LUMO } \\
\text { HOMO-2 } \rightarrow \text { LUMO+I }\end{array}$ \\
\hline & & 386 & 0.4794 & $\begin{array}{l}\mathrm{HOMO}-2 \rightarrow \text { LUMO } \\
\mathrm{HOMO} \rightarrow \text { LUMO+I }\end{array}$ \\
\hline
\end{tabular}

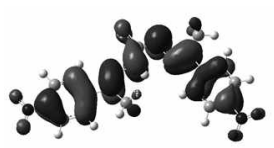

HOMO-2

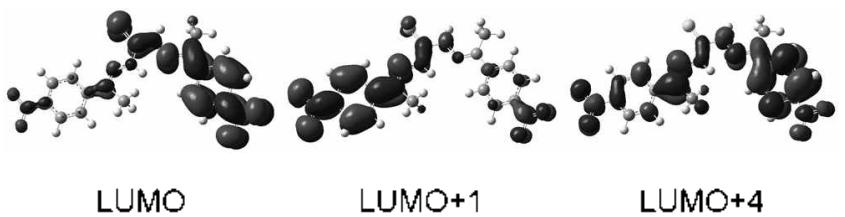

Figure 2. Molecular obtials active in the electronic transitions of the title compound.

Table 3. Themodynamic properties of the title compound at different temperatures

\begin{tabular}{cccc}
\hline$T(\mathrm{~K})$ & $\begin{array}{c}C_{p \cdot m}^{0} \\
\left(\mathrm{~J} \cdot \mathrm{mol}^{-1} \cdot \mathrm{K}^{-1}\right)\end{array}$ & $\begin{array}{c}S_{m}^{0} \\
\left(\mathrm{~T} \cdot \mathrm{mol}^{-1} \cdot \mathrm{K}^{-1}\right)\end{array}$ & $\begin{array}{c}H_{m}^{0} \\
\left(\mathrm{k} \cdot \mathrm{T} \cdot \mathrm{mol}^{-1}\right)\end{array}$ \\
\hline 200.0 & 305.42 & 647.23 & 36.80 \\
298.1 & 421.09 & 790.90 & 72.50 \\
300.0 & 423.20 & 793.51 & 73.28 \\
400.0 & 529.63 & 930.22 & 121.06 \\
500.0 & 617.83 & 1058.23 & 178.59 \\
600.0 & 688.37 & 1177.35 & 244.03 \\
700.0 & 744.74 & 1287.86 & 315.79 \\
800.0 & 790.40 & 1390.38 & 392.63 \\
\hline
\end{tabular}

$\mathrm{S}=\mathrm{C}$ bond. two nitro-groups. two phenyl rings, two $\mathrm{C}=\mathrm{N}$ bonds and two N-N bonds. all take part in the electronic transitions. which are corresponding to the intermolecular $n-\pi^{*}$ and $\pi-\pi^{*}$ electron transitions

On the basis of statistical thermodynamic and vibrational analysis at B3LYP/6-3 IG* level. the standard thermody namic functions: heat capacity $\left(C_{p ;}^{\prime}\right)$. entropy $\left(S_{m}^{\prime}\right)$ and enthalpy $\left(H_{m}^{(1}\right)$ were obtained and listed in Table 3 . The scale factor for the frequencies is 0.96 . As observed from Table 3 , all the values of $C_{p, m}^{\prime 2} S_{m}^{5}$ and $H_{m}^{\prime \prime}$ increase with the increase of temperature from 200.0 to $800.0 \mathrm{~K}$. which is attributed to the enhancement of the molecular vibration while the temperature increases.

The correlations linear equations between these thermodynamic properties and temperatures $T$ are as follows:

$$
\begin{aligned}
& C_{p, m}^{d}=20.6011+1.5761 T-7.694^{*} 10^{-4} T^{2}\left(R^{2}=0.9999\right) \\
& S_{m}^{\prime)}=330.1593+1.6749 T-4.3757 * 10^{-4} T^{2}\left(R^{2}=0.999999\right) \\
& H^{(1)}=-20.8604+0.1976 T+4.017 * 10^{-4} T^{2}\left(R^{2}=0.9998\right)
\end{aligned}
$$

These equations could be used for the further studies of the title compound.

\section{Experimental Section and Calculational Method}

Synthesis. All chemicals were obtained from a commercial source and used without further purification.

$p$-Nitroacetophenone $(0.02 \mathrm{~mol})$ and thiocarbonoly drazide $(0.01 \mathrm{~mol})$ were mixed in ethanol solution $(50 \mathrm{~mL})$ and stirred with refluxing. 4 h later. mary light-yellow solids were observed and then the reaction was stopped and the mixture was cooled to room temperature. The yellow solids were obtained by filtration and dried at roon temperature. Yield $89 \%$ mp. 204-205 ${ }^{\circ} \mathrm{C}$. IR: v 3426 (m), 3109 (m), 2966 (m), 1579 (m), $1516(\mathrm{vs}), 1340$ (vs), $1276(\mathrm{~m}) .1224(\mathrm{~s}), 1109(\mathrm{~s}), 1064(\mathrm{~m}), 875$ (s), 789 (w). 753 (n), 692 (w), 609 (w), 543 (w) cm cm $^{-1}$. Found: C, 48.79: H. 4.34: N. $20.09 \%$. Calc. for $\mathrm{C}_{34} \mathrm{H}_{36} \mathrm{~N}_{12} \mathrm{O}_{10} \mathrm{~S}_{2}:$ C. 48.66 : H. 4.23 ; N. $20.18 \%$. ${ }^{\mathrm{H}} \mathrm{H}$ NMR $\left(400 \mathrm{MHz} . \mathrm{CDCl}_{3}\right)$ ò 1.28 (s, $6 \mathrm{H},-\mathrm{CH}_{3}$ ). 7.28 (s. 2H, $\left.-\mathrm{NH}\right) .7 .91-8.32\left(\mathrm{~m}, 8 \mathrm{H},-\mathrm{C}_{6} \mathbf{H}_{4}\right)$.

For the compound. single crystals suitable for X-ray measurements were obtained by recrystallization from acetic ether at room temperature.

Crystal structure detemination. The diffraction data were collected on a Enraf-Nonius CAD-4 diffractometer with graphite-monchromated $k o-K \alpha$ radiation $(i=0.71073 \AA . T=$ $295(2) \mathrm{K}$ ). The technique used was $\omega$ scan with limits 1.58 to $25.00^{\circ}$. The structure of the title compound was solved by direct method and refined by least squares on $F^{2}$ by using the SHELITL software package. All non-hydrogen atoms were anisotropically refined. The approximate positions of the four water $\mathrm{H}$ atoms were firstly obtained from a difference map. Then, the four atoms were placed in 'ideal' positions. The other lydrogen atom positions were fixed geometrically at calculated distances and allowed to ride on the parent carbon and nitrogen atoms. The molecular graphics were plotted using SHELITL. Atomic scattering factors and anomalous dispersion corrections were taken from Intenational Tables for X-ray Cry stallograplyy. ${ }^{28}$

Computational methods. The crystal structure of the title 
compound was used as initial molecular geometry. then it was optimized by using MM+ molecular modeling and semiempirical AMl mehtod ${ }^{29}$ (HYPERCHEM 6.0. Hypercube. Ont.. Canada). In the next step. B3LYP (Becke's three parameter hybrid finctional using the LYP correlation functional) calculations at basis set $6-31 \mathrm{G}^{*}$ by the Beny method ${ }^{3(1}$ were performed with the Gaussian 03 software package. ${ }^{31}$ Vibrational frequencies calculated ascertain the structure was stable (no imaginary frequencies). The thermody namic properties of the title compound at different temperatures were calculated on the basis of vibrational analyses. Electronic absorption spectra were calculated by using time-dependent density functional theory (TDDFT) ${ }^{32 \cdot 34}$ method at $6 \cdot 31 \mathrm{G}^{*}$ basis set. Natural Bond Orbital (NBO) analy ses were performed on the optimized structures. ${ }^{35}$ All calculations were performed on a DELL PE 2850 server and a Pentium IV computer using the default convergence criteria.

Supplementary Data Crystallographic data for the structure reported here have been deposited with Cambridge Crystallographic Data Center (Deposition No. CCDC - 719724). The data can be obtained free of charge via www.ccdc.cam.ac.uk/ conts/retrieving.html (or from the CCDC, 12 Union Road. Cambridge CB2 IEZ, UK: fax: +\$41223 336033: e-mail: depositaccdc.cam.ac.uk). Some selected geometric parameters for both experimental and calculational data can be obtained from the author directly.

Acknowledgments. This work was supported by Jiangsu Key Laboratory for Chemistry of Low-Dimensional Materials P. R. China (JSKCO8047) and Fund of Huaiyin Normal University (07HSBS004. 08HSJSK003).

\section{References}

1. Di Grandi, M. T.; Curran, K. I.: Feigelson, G.; Prashad, A.: Ross, A. A.; Visalli, R.; Fairhurst, T.; Feld, B; Bloom, J. D. Bioorg. Hed. Chem. Lett. 2004, $14,4157$.

2. Han, T: Cho, J. H.: Oh, C. H. Emr. J. Med Chem 2006, 41,825 .

3. Kaymakcioglu, B. K.; Rollas, S; Korcegez, E.; Aricioglu, F. Eur. J. Pham. Sci. 2005, 26,97.

4. Rostom, S. A. F. Bioory. Afed Chem. 2006, $14,6475$.

5. Heck, R.; Marsura, A. Tetrahedron Lett. 2003, + - 1533.

6. Cao, C. L:; Ye, M C.; Sun, X. L.; Tang, Y. Org. Lett. 2006, \&, 2901.

7. Liu, K.; Cui, H. F.; Nie, J.: Dong, K. Y.: Li, X. J.: Ma, J. A. Ong. Lent. 2007, 9, 923 .

8. Wang, X. M: Zhu, T; Zheng, L. Y.: Li, Y. X: Zheng, T. F.; Zhang, S. Q.: Bai, T. Chin. J. Org. Chem 2006, 26, 660.

9. Tran, F. F.; Zhao, P. S.; Hou, Y. X. Chin. J. Struct Chem. 2004, 23,1256

10. Tian, F. F.; Zhao, P. S.; Hou, Y. X. Stwit. Chem. 2005, 16, 361 .

11. Tian, F. F.; Zhao, P. S.; Bai, Z. S.: Zhang, L. Struct Chem. 2005, 16,635 .

12. Tian, F. F.: Wang, K. F.; Zhao, P. S.; Zhuang, R. R.; Zheng, T. Struct. Chem. 2006, 17, 539 .

13. Zhao, P. S.; Li, R. Q.; Zhang, L. L.: Jian, F. F. Polish J. Chent.
$2006,80,2031$

14. Li, C. H.; Wang, Q $:$ Xu, Y. Q $:$ Hu, C. W. Chin. J. Sintct Chem. $2008,27,187$.

15. Kasai, K.: Aoyagi, M; Fujita, M. J. Am. Chem. Soc. 2000, 122, 2140 .

16. Kitagawa, S.: Kitaura, R.; Noro, S. I. Angew. Chem., Int. Ed. $2004,+3,2334$

17. Hoshino, N.; Ito, T.; Nihei, M: Oshio, H. horg. Chent Commthn. $2003,6,377$

18. Khandar, A. A.: Nejati, K. Polvhedron 2000, 19,607.

19. Foresman, I. B.: Frisch, A. Exploning Chemistry with Electronic Strtcture 14thods, 2nd ed.; Gaussian, Inc.: Pittsburgh, PA, 1996.

20. Ruud, K.; Helgaker, T.; Kobayashi, R.; Jorgensen, P.; Bak, K. L. J. Chem Phys. 1994, 100,8178.

21. Hehre, W. T.; Radom, L.: Schleyer, P. R.; Pople, T. A. Ab Initio Molecular Orbital Theon, Wiley: New York, 1986.

22. Parr, R. G.: Yang, W. T. Density Fumctional Theon of Atoms and Molecules; Oxford University Press: New York, 1989 and references therein.

23. Ziegler, T. Chem. Rev. 1991,91,651 and references therein.

24. Wolinski, K.; Hinton, I. F.: Pulay, P. J. Am. Chem. Soc. 1990. 112,8251 .

25. Schreckenbach, G.; Ziegler, T. J. Phys. Chem. 1995, A 99, 606.

26. Han, F.; Bao, Y. H.; Yang, Z. G.; Fyles, T. M.; Zhao, J. Z.; Peng, X. J.; Fan, J. L.; Wu, Y. K; Sun, S. G. Chem. Ettr, J. 2007, 13, 2880 .

27. Sheldrick, G. M. SHELITL, v5 Reference MAmual, Siemens Analytical X-Ray Systems: Madison, WI, 1997.

28. Wilson, A. J. Intemational Table for I-Rav Crystallography: Kluwer Academic: Dordrecht, The Netherlands, 1992; Vol. C, Tables 6.1.1.4 (pp 500-502) and 4.2.6.8 (pp 219-222), respectively.

29. Dewar, M. T. S.; Zoebisch, E. G.: Healy, E. F. J.Am Chem. Soc. $1985,107,3902$

30. Peng, C: Ayala, P. Y.; Schlegel, H. B.; Frisch, M. T. J. Comput. Chem, 1996, 17, 49

31. Frisch, M. I.; Trucks, G. W; Schlegel, H. B.: Scuseria, G. E.; Robb, M. A.; Cheeseman, I. R.; Montgomery, J. A.: Vreven, JI., T.; Kudir, K. N.; Burant, J. C.; Millam, J. M.; Iyengar, S. S.; Tomasi, I.; Barone, V.; Mennucci, B.; Cossi, M.; Scalmani, G.; Rega, N.; Petersson, G. A.; Nakatsuji, H.; Hada, M.; Ehara, M.; Toyota, K.: Fukuda, R.: Hasega wa, J.: Ishida, M.: Nakạima, T.; Honda, Y.; Kitâ, O.: Nakai, H.: Klene, M.: Li, X.; Knos, J. E.; Hratchian, H. P.; Cross, J. B.; Adamo, C.; Taramillo, T.; Gomperts, R.; Stratmann, R. E: Yazvev, O.; Austin, A. I: Cammi, R.; Pomelli, C.; Ochterski, J. W.; Ayala, P. Y.; Morohuma, K; Voth, G. A.; Salvador, P.; Dannenbers. I. I.; Zakrzenski, V. G.; Dapprich, S.; Daniels, A. D.: Strain, M. C.; Farkas, O.: Malick, D. K.; Rabuck, A. D.; Raghavachar, K.; Foresman, J. B.: Ortiz, J. V.; Cui, Q.; Baboul, A. G.; Clifłord, S.; Cioslowski, T.; Stefanov, B. B.; Liu, G.; Liashenko, A.; Piskorz, P.; Komaromi, I.; Martin, R. L.; Fos, D. T.: Keith. T.: Al-Laham, M. A.; Peng. C. Y.; Nanayakkara, A.: Challacombe, M.: Gill, P. M. W.: Johnson, B.; Chen, W.: Wong, M. W.: Gonzalez, C.; Pople, J. A. Gaussian, Inc: Wallingford, CT, 2004.

32. Petersilka, M.; Gossmanu, U. T.; Gross, E. K. U. Phys. Rev Lett. $1966,76,1212$

33. Banemschmitt, R; Allrichs, R. Chem. Phws Lett 1996, $256,454$.

34. Jamorski, C.; Casida, M. E.; Salahub, D. R. J Chem. Phys 1996, $104,5134$.

35. Runge, E.; Gross, E. K. U. Phws. Rev. Lett. 1984, 52, 997. 